\title{
Supply Chain Joint Inventory Management and Cost Optimization Based on Ant Colony Algorithm and Fuzzy Model
}

\author{
Wenfang YU, Guisheng HOU, Pengcheng XIA, Jingjing LI
}

\begin{abstract}
With the advancement of the marketization process, inventory management has transformed from a single backup protection function to an essential function for enterprises, which helps to survive and develop. Inventory control in supply chain management is the important content of supply chain management. The new management mode makes inventory management present many new characteristics and problems compared with traditional inventory management. From the view of system theory and integration theory, it is imperative to re-examine the problem of inventory control, put forward new inventory management strategies adapted to integrated supply chain management, and improve the integration of the whole supply chain, which can enhance the agility and market response speed of enterprises. Based on the in-depth study of the joint inventory management model, this paper analyzed the current situation of the joint inventory management to optimize the inventory. In view of the achievements and shortcomings of the current research, a more systematic and improved optimization model of the supply chain inventory was proposed by using the basic ideas of ant colony algorithm and fuzzy model.
\end{abstract}

Keywords: ant colony algorithm; cost optimization; fuzzy model; inventory management; supply chain

\section{INTRODUCTION}

The rapid development of the economy has brought about tremendous changes in the way the market is circulated. The logistics industry is an important growth point for the development of the national economy. It can increase the scale of regional employment, optimize the regional industrial economic structure, and reduce the economic operating costs at the same time. Suppliers play an important role in industrial production and life. According to statistics, in the total cost of construction projects consisting of products and services, the proportion of suppliers is more than $80 \%$. In order to meet the needs of customers, it is particularly important to meet the needs of suppliers and the products and services they provide to meet their needs and how to deliver them [1, 2]. Engineering supply chain management is currently widely used, increasing profits while reducing costs. At present, supply chain management ideas have applied to many industries, such as aviation, retail, and manufacturing, especially in the manufacturing industry. From the trend of logistics development, the distribution centre should not only be a node in the logistics supply chain, but also only have the distribution tasks for distributors, retailers, and customers on the logistics nodes, perform general logistics functions. It is the key to the entire logistics network to carry out functions such as command and dispatch and processing information, and it is receiving wide attention from all quarters.

In the material inventory, materials of the same type are often used, and the role played by them is quite different. Therefore, in the research of material inventory management model and cost optimization process, it is necessary to analyze the application scenario. When a small number of spare parts are left, they are generally treated as special spare parts, which are only used for important needs, thus maximizing the overall benefits. Wang, [3] introduced definitions of multiple demand categories and important levels in inventory management. The level of importance is defined as follows. When the stock level drops to a certain level and all remaining materials are considered important spare parts, the stock level is an important level. Jiang [4] assumes that various requirements are subject to the Poisson distribution process, and that the order quantity and the important level are independent of time, and on this basis, the optimal importance level strategy is derived. Liu [5] studied a similar model, assuming that out-of-stocks could be replenished. Zhou [6] divided the requirements into two categories, and estimated the optimal order quantity, basic inventory level, and important level under the condition of ordering cost, inventory holding cost and sales loss cost were minimized. Similarly, Zamarripa [7] analyzed similar models and assumed that out of stock could replenish. Chang [8] simplifies the model, assuming that the reorder point level is an important level. On this basis, the spare parts order inventory model is analyzed. When the spare parts inventory level reaches the reorder point level, the secondary spare parts begin to be out of stock before the important spare parts. When all the remaining important materials are consumed by important demand, important spare parts are also out of stock. Since the customer starts at the lead-time, the order is started at the reorder point [9]. Therefore, the material will be replenished instantaneously at the end of the early period, at which point the customer will end the shortage of important spare parts and secondary spare parts. Under normal circumstances, the manufacturer will start the machine to start producing spare parts when the customer places the order, and must produce enough spare parts to supply the customer at the end of the lead-time. Therefore, the lead-time information has been shared between the customer and the manufacturer. Sajadieh in the literature [10] assumes that the lead-time order only affects the customer's inventory change level and ordering behaviour to study the joint inventory model. The study has certain limitations. The main reason is that the sharing of lead-time information is not considered in the production of producer's production inventory model, so the impact of the lead-time information on the producer's production inventory model is not considered.

The goal of material distribution system in supply chain management is to ensure adequate supply with lower logistics cost and higher service level within the scope of service $[11,12]$. The location of distribution centres and the selection of distribution routes are the most important factors affecting the service quality and cost of distribution system. In order to optimize the distribution system, the location and route selection of distribution centre should be 
optimized comprehensively [13-15]. Therefore, this paper proposes to optimize the location of distribution centres through genetic algorithm, and then further optimize the distribution routes through improved ant colony algorithm. Under the mode of supply chain management, the competition among individual enterprises is transformed into the competition among supply chains $[16,17]$. To enhance the overall competitiveness of the supply chain, we should not only provide the best service, but also strive to maintain the most reasonable cost. Inventory cost is the most important component of supply chain cost, which generally accounts for more than $30 \%$ of the total cost. Therefore, the study of inventory cost control in supply chain is of great significance to improve the performance of supply chain.

\section{PRINCIPLE AND MODEL OF BASIC ANT COLONY ALGORITHMS}

Ants are a kind of social insects. After a lot of research, it has been found that ants can transmit information through a substance called exogenous hormone in the course of their movement. They leave this substance on the path. At the same time, ants can perceive the existence and intensity of this substance in the process of movement, and use this substance to guide their movement direction. Therefore, the more ants walk along a certain path, the higher the intensity of exogenous hormones left behind, and the greater the probability that the latter will choose the path. It is through the exchange of information among ants that the purpose of searching for food is achieved [18, 19].

The process of ant colony searching for food is very similar to the famous Travel Salesman Problem (TSP). The ant colony algorithm model is illustrated by the TSP problem of $\mathrm{n}(n=0,1, \ldots, n-1$, denoting city number $)$ cities. Let $m$ be the number of ants in the ant colony, $d_{i j}(i, j=1$, $2, \ldots, n)$ denote the distance between city $i$ and city $j$, and $b_{i}(t)$ denote the number of ants in city $i$ at $t$ time.

$$
m=\sum_{i=0}^{n-1} b_{i}(t)
$$

Let $f_{i j}(\mathrm{t})$ be the residual information on the $i j$ connection at $t$ time, and $f_{i j}(t)=C(C$ is constant $)$ at this time because the information on each road is equal at the initial time. In TSP problems, the enlightenment information $Z_{i j}$, which is generally transferred from city $i$ to city $j$, is as follows:

$$
Z_{i j}=\frac{1}{d_{i j}}
$$

Let $P_{i j}^{k}(t)$ be the probability that ant $k$ moves from position $i$ to position $j$ at time $t$, then:

$$
P_{i j}^{k}(t)=\left\{\begin{array}{l}
\frac{f_{i j}^{T}(t) Z_{i j}^{U}(t)}{\sum f_{i s}^{T}(t) Z_{i s}^{U}(t)} \\
0
\end{array}\right.
$$

In the formula: $T$ - Information heuristic factor reflects the strength of random factors in ant colony path selection; $U$ - expectation heuristic factor reflects the strength of deterministic factors in ant colony path selection.

The pheromones left by ants volatilize over time, so after each ant completes its visit to all $n$ cities (after a cycle ends), the residual information must be updated. Update the amount of information according to the following formula.

$$
f_{i j}(1+n)=d \times f_{i j}(t)+\Delta f_{i j}
$$

In the formula: $d$ - the residue coefficient of pheromone, $d \in(0,1) ; \Delta f_{i j}$ - Incremental information on path ij in this cycle; $\Delta f_{i j}^{k}$ is the amount of information left on path ij by the $k$ ant in this cycle.

M. Dorigo proposed an ant cycle system. In an ant model, $\Delta f_{i j}^{k}$ is determined by the following formula:

$$
\Delta f_{i j}^{k}=\left\{\begin{array}{l}
\frac{Q}{L_{k}}, \text { if the } k \text { ant passes through } i j \text { in this cycle } \\
0, \text { othersise }
\end{array}\right.
$$

In the formula: $Q$ - The total amount of information released by ants through the path, constant; $L_{k}$ - The length of the path that the $k$ ant travels in this cycle.

\section{RESEARCH ON JOINT INVENTORY MANAGEMENT COST MODEL}

\subsection{Connotation of Joint Inventory Management}

Joint inventory management is an inventory management method based on coordination centre. This method embodies the idea that by strengthening inventory control under supply chain management, the system and integration of supply chain can be improved, the agility and responsiveness of enterprises can be enhanced. Because each node enterprise in the supply chain only makes production and supply decisions based on the demand information from its adjacent downstream enterprises, the untruthfulness of demand information will go up along the supply chain upstream, resulting in the phenomenon of step-by-step amplification [20, 21]. Because of this demand amplification effect, upstream suppliers tend to maintain higher inventory levels than downstream suppliers. Nowadays, the establishment of the inventory safety quantity of domestic enterprises is mostly established by the previous work experience value and the general inventory safety analysis formula, and the perfect inventory safety system has not been reached. At present, most domestic companies set the inventory safety quantity based on the experience value of previous years, and in order to ensure the service level, the inventory safety quantity is generally set higher, which leads to problems such as high company commodity cost and insufficient cash flow. Because of accurately grasping the market demand, the service level is set for the company, and the corresponding inventory safety quantity is calculated by the formula [22]. Therefore, Joint Inventory Management (JMI) is proposed to solve the problem of "demand amplification" and improve the synchronization of supply 
chain, which is caused by the independent inventory operation mode of each node enterprise in the supply chain system. It embodies the new cooperative relationship of strategic supplier alliance and is a risk-sharing inventory management model.

\subsection{Cost Comparison Model in Joint Inventory}

(1) Hypothesis.

The so-called two-stage supply chain manufacturing enterprises refer to the upstream and downstream enterprises as suppliers to provide spare parts and other materials for the downstream enterprises, while the downstream enterprises as core enterprises or users to purchase their own materials from the upstream enterprises.

Now the ideal state of a two-stage supply chain is considered with one manufacturer and one retailer. Suppose the manufacturer adopts JIT production mode and has unlimited productivity $[23,24]$. Retailers adopt $(0, Q)$ inventory strategy, that is, when inventory drops to 0 , order to restore inventory to $Q$.

The retailer purchases goods from the manufacturer, assuming that the retailer's demand for the goods is continuous and uniform, and the annual demand is constant $R$. Retailer's parameters are as follows. The annual storage $\operatorname{cost} C_{1}$ used for each unit of commodity, ordering cost $C_{3}$ used for fixed costs, such as handling fees, telecommunications exchanges and outgoing personnel procurement costs, related to the number of orders, but not to the number of orders. Manufacturer's parameters are each assembly cost $C_{2}$ (preparation of production materials, organization of production personnel, and other costs, independent of production).

\section{(2) Model analysis}

In the traditional mode, manufacturers and retailers set up their own warehouses and manage their own inventory, without considering the problem of sharing among partners. In the absence of cooperation, each channel member will make decisions from their own perspective to minimize operating costs, rather than cooperating to reduce the cost of the entire supply chain. Because the manufacturer has unlimited productivity, the order of the retailer can be satisfied. The retailer's cost is equal to the order cost plus the inventory cost, and the retailer's cost function is as follows:

$$
C_{R}=\frac{R}{Q} C_{3}+\frac{Q}{2} C_{1}
$$

The total annual cost of the retailer is the sum of the storage cost and the order cost.

$$
C_{R}^{0}=\frac{C_{1} Q_{o}}{2}+\frac{C_{3} R}{Q_{o}}=\sqrt{2 R C_{1} C_{3}}
$$

The manufacturer's fee is the assembly cost, which is expressed as follows.

$$
C_{M}^{0}=\frac{C_{2} R}{Q_{o}}=\frac{C_{2}}{2 C_{3}} \sqrt{2 R C_{1} C_{3}}
$$

The cost of the whole supply chain is as follows.

$C_{D}^{0}=C_{M}^{0}+C_{R}^{0}=\left(1+\frac{C_{2}}{2 C_{3}}\right) \sqrt{2 R C_{1} C_{3}}$

Under the Joint Inventory Management, the manufacturer will cancel its finished product inventory and place the inventory directly in the raw material warehouse of the retailer. At this time, the cost function of the supply chain is:

$C_{D}=\frac{R}{Q}\left(C_{2}+C_{3}\right)+\frac{Q}{2} C_{1}$

The optimal inventory level of supply chain with the same first derivative is as follows.

$Q_{1}=\sqrt{\frac{2\left(C_{1}+C_{3}\right) R}{C_{1}}}>Q_{0}$

It can be seen that the inventory level of traditional supply chain is lower than that of supply chain under joint inventory management. The cost of the supply chain consists of the retailer and the cost of the manufacturer. The cost of the retailer is as follows:

$C_{R}^{1}=\frac{1}{2}\left(\sqrt{\frac{C_{1}+C_{3}}{C_{3}}}+\sqrt{\frac{C_{3}}{C_{2}+C_{3}}}\right)$

$\sqrt{2 R C_{1} C_{3}} \geq \sqrt{2 R C_{1} C_{3}}=C_{R}^{0}$

It can be seen that the overall cost of the supply chain has been reduced.

\subsection{The Profit Distribution between Manufacturer and Retailer in Joint Inventory}

In the above analysis, we can see that in the joint inventory management, the manufacturer's cost decreases while the retailer's cost increases [25]. Therefore, in the process of realizing the optimization of supply chain, we must consider the redistribution of the interests of both the supplier and the demander, so that the manufacturer can reduce the cost of the retailer, and at the same time, reduce or keep the cost of the retailer unchanged. So both the supplier and the demander can benefit from the cooperative game.

In the above model, both the supplier and the demander determine the optimal inventory level from the perspective of optimizing the supply chain, to minimize the total cost of the supply chain as $Q_{1}$. Suppose in this case, the cost savings obtained by the manufacturer are $\Delta C_{M}$ and the cost increment of the retailer is $\Delta C_{R}$, and the manufacturer gives the retailer a benefit compensation $G$ to compensate for the benefit of the retailer's cost.

The benefit of cost caused by the retailer ordering under the optimal inventory under the joint inventory is as follows. 
$\Delta C_{R}=C_{R}^{1} \cdot C_{R}^{0}$

The savings of manufacturer's cost caused by the cooperation between supplier and demander are as follows:

$\Delta C_{M}=C_{M}^{1} \cdot C_{M}^{0}$

Therefore, from the perspective of retailers, the amount of benefit compensation $\mathrm{G}$ should not be less than the benefit of inventory cost, that is $G \geq \Delta C_{R}$. From the manufacturer's point of view, retailer's benefit compensation $G$ should not be greater than the cost savings of supplier after cooperation, that is $G \leq \Delta C_{M}$. Therefore, $\Delta C_{R} \leq G \leq \Delta C_{M}$.

Under the level of joint inventory management, after the cooperation between supply and demand, the two sides will play a game for the benefit distribution. Retailers want $G$ to be close to $\Delta C_{M}$ while manufacturers want $G$ to be close to $\Delta C_{R}$. At this time, as long as $G \in\left(\Delta C_{R}, \Delta C_{M}\right)$, the cooperation between supply and demand is an optimization of supply chain inventory. As for the value of $G$ in the above range, it depends entirely on the game strength of both sides and the contribution of both sides to the improvement of supply chain. When the manufacturer is an oligopoly, or the retailer's demand accounts for a small proportion of the total output of the manufacturer, or the manufacturer has competitive advantages in terms of quality, cost and characteristics [26, 27]. When the cost of retailer changing manufacturer is high, $G$ tends to approach the lower bound of the interval. When the market competition is perfect or the demand of retailer accounts for a large proportion of the total output of supplier, or the product is mainly popular. When the cost of retailer changing manufacturer is low, $G$ tends to approach the upper bound of the interval.

\section{ESTABLISHMENT OF SUPPLY CHAIN INVENTORY MODEL UNDER JOINT INVENTORY MANAGEMENT STRATEGY}

\subsection{Principles of Supply Chain Modeling}

The following principles should be followed in establishing supply chain models:

1) The principle of combining bottom-up and top-down. The bottom-up approach is from the local to the global, while the top-down approach is the opposite. The supply chain design should consider both the global and the local.

2) The principle of conciseness. In order to enable the supply chain to respond to the market flexibly and quickly, each node of the supply chain should be streamlined, dynamic, and able to achieve rapid business combination.

3) Principle of complementarity and superiority. The selection of each node in the supply chain should follow the principle of strong alliance to achieve the purpose of using external resources.

4) The principle of coordination. The performance of supply chain depends on whether the supply chain partnership is coordinated or not, and a harmonious and coordinated system can play its best role.

5) Dynamic principle. It is necessary to predict the impact of various uncertainties on the operation of supply chain and reduce the information delay and distortion in the process of information transmission.

6) The principle of innovation. In the design of supply chain, we need to examine the original management model and system from a new perspective, and make bold innovation and design.

7) The development of the system structure of strategic principle supply chain should have a strategic vision, focusing on keeping in line with long-term planning and enterprise strategic planning.

\subsection{Inventory Flow Chart before and after Implementing Joint Inventory Management}

In this paper, by referring to some achievements of existing scholars and making up for some shortcomings of existing research, this paper adopts the joint inventory management to optimize the inventory management in Two-echelon Supply Chain [28-31]. Before the implementation of footwork, enterprises in the supply chain implement a decentralized inventory system, retailers own their own inventory, and when faced with shortage, retailers will urgently purchase from nearby external suppliers to avoid the loss of shortage [32]. The flow chart between supplier and retailer is shown in Fig. 1.

When the strategy is adopted, the decentralized inventory system is changed into a centralized inventory system. A distribution center is established to centralize the inventory of all retailers. The retailers no longer hold the inventory, and the distributors hold the entire inventory. All retailers are confronted with demand forecasting and delivery to the distribution center. The distribution center unifies the order demand to the supplier, the supplier only delivers to the distribution center, and the distribution center coordinates and distributes the goods among the retailers. At this point, the retailer is facing a shortage, no longer purchases from outside the supply chain, but waits for replenishment by the distribution center. In this case, the flow chart between suppliers, distribution centers, and retailers is shown in Fig. 2.

The biggest difference before and after the implementation of the strategy is to change the retailer's decentralized inventory to centralized inventory, which can effectively reduce the system's safe inventory and average inventory [33]. Because Joint Inventory Management (JMI) has the function of risk sharing, that is, if the demand of different places is processed together, the demand variability can be reduced. Whenever the demand in a joint inventory management system is lower than the average demand in a market, the demand is lower than the average demand. Warehouses can redistribute items originally allocated to one market to another market $[34,35]$. The process of redistributing inventory in a decentralized management system is not feasible. In addition, the standard deviation coefficient is bigger, the profit from the joint inventory management system is bigger, that is, the bigger the profit from risk sharing [36]. Because the reduction of the average inventory is mainly achieved by reducing the safe inventory and the larger the standard deviation coefficient, the more significant the reduction of the safe inventory will be after the implementation of joint 
inventory management. Therefore, it has great benefits to reduce the average inventory of retailers and improve the overall benefits of the supply chain.

The average inventory of the system consists of two parts, which are the average inventory $Q / 2+$ SS, in which $Q$ represents the order quantity for each time, and SS represents the safe inventory.
After the centralized retailer's inventory, the safe inventory is reduced, which reduces the average inventory [37]. It can also be concluded from the formula that the larger the standard deviation, the greater the extent of reduction of safe inventory, that is, the greater the revenue from the joint inventory management system.

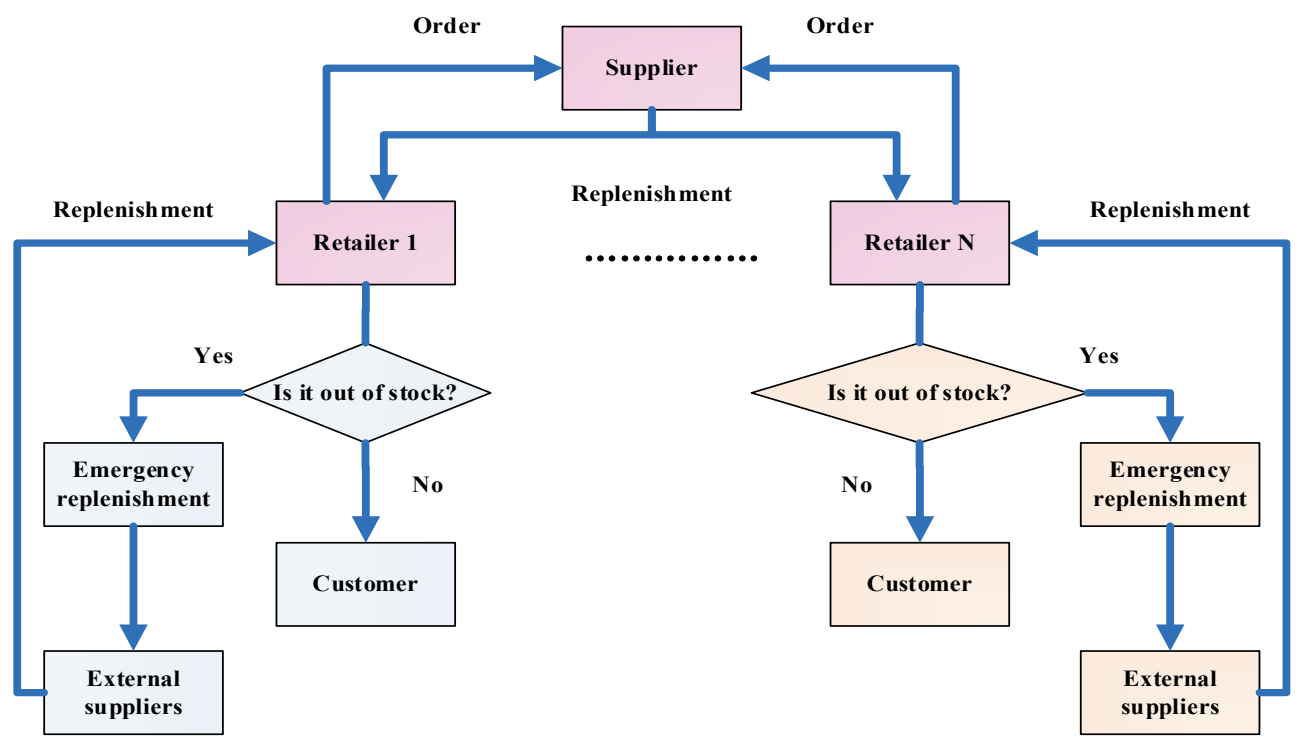

Figure 1 Job flow chart before implementation of JMI

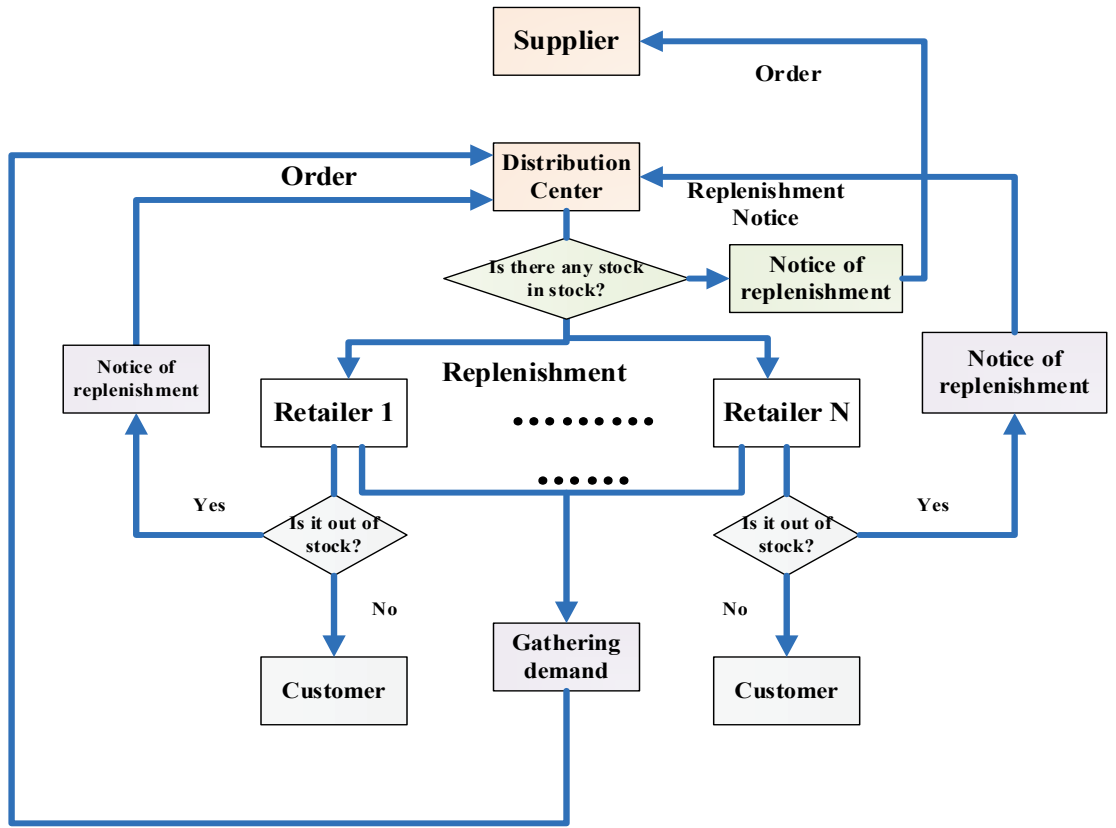

Figure 2 Job flow chart after implementation of JMI

\section{EXPERIMENT AND RESULTS \\ 5.1 Instance Data}

Taking Fig. 1 as an example, the supply chain core enterprise under NM mode produces two kinds of products $\mathrm{A}$ and $\mathrm{B}$, and receives three orders from three distributors, each of which has demand for two kinds of products. The processing sequence of $\mathrm{A}$ and $\mathrm{B}$ products is $P_{1} \rightarrow P_{2} \rightarrow P_{3} \rightarrow P_{4} \rightarrow P_{5} \rightarrow P_{6}$ and $P_{2} \rightarrow P_{1} \rightarrow P_{3} \rightarrow P_{6}$ respectively. The orders of the same distributor decomposed and numbered according to the two products
(A and B). Each order has a final delivery date constraint (the same distributor may have different delivery dates for the two products $\mathrm{A}$ and $\mathrm{B}$ ). Contact with process providers to obtain process-related data such as total production time and total production cost for each order at each process provider [38, 39]. The time required for each process workshop of the core manufacturer to complete each process with the co-manufacturer is shown in Tab. 1, and the cost for each process is shown in Tab. 2. The product type, quantity, delivery time requirement and transportation cost of each order are shown in Tab. 3. 


\begin{tabular}{|c|c|c|c|c|c|c|c|c|c|}
\hline Distributor order & Working procedure & P1 & P21 & P22 & P3 & P41 & P42 & P51 & P52 \\
\hline Distributor 1 & $\begin{array}{l}1 \\
2\end{array}$ & $\begin{array}{c}7 \\
19\end{array}$ & $\begin{array}{l}2 \\
6\end{array}$ & $\begin{array}{l}3 \\
4\end{array}$ & $\begin{array}{c}4 \\
10\end{array}$ & $\begin{array}{l}3 \\
1\end{array}$ & $\begin{array}{l}6 \\
1\end{array}$ & $\begin{array}{l}5 \\
1\end{array}$ & $\begin{array}{l}6 \\
1\end{array}$ \\
\hline Distributor 2 & $\begin{array}{l}3 \\
4\end{array}$ & $\begin{array}{l}10 \\
17\end{array}$ & $\begin{array}{l}3 \\
5\end{array}$ & $\begin{array}{l}5 \\
3\end{array}$ & $\begin{array}{l}6 \\
8\end{array}$ & $\begin{array}{l}5 \\
1\end{array}$ & $\begin{array}{l}9 \\
1\end{array}$ & $\begin{array}{l}6 \\
1\end{array}$ & $\begin{array}{c}6 \\
14\end{array}$ \\
\hline Distributor 3 & $\begin{array}{l}5 \\
6\end{array}$ & $\begin{array}{l}14 \\
10\end{array}$ & $\begin{array}{l}4 \\
3 \\
\end{array}$ & $\begin{array}{l}6 \\
2\end{array}$ & $\begin{array}{l}8 \\
5\end{array}$ & $\begin{array}{l}6 \\
1\end{array}$ & $\begin{array}{c}12 \\
1\end{array}$ & $\begin{array}{l}8 \\
1\end{array}$ & $\begin{array}{l}8 \\
8\end{array}$ \\
\hline
\end{tabular}

\begin{tabular}{|c|c|c|c|c|c|c|c|c|}
\hline Procedure order & P1 & P21 & P22 & P3 & P41 & $\mathrm{P} 42$ & P51 & P52 \\
\hline 1 & 134 & 11.7 & 12.7 & 4 & 17 & 16.6 & 6.8 & 31 \\
\hline 2 & 201 & 22.4 & 2 & 17. & 1 & 1 & 1 & 67 \\
\hline 3 & 183 & 15.9 & 17.4 & 5.3 & 24.8 & 22.7 & 8 & 43 \\
\hline 4 & 181 & 20.2 & 24.2 & 6.5 & 1 & 1 & 1 & 60.5 \\
\hline 5 & 247 & 22.3 & 24.3 & 7.1 & 34.9 & 32 & 16.1 & 61 \\
\hline 6 & 101 & 11.7 & 14.1 & 4.1 & 1 & 1 & 1 & 34 \\
\hline
\end{tabular}

Table 3 Order details

\begin{tabular}{|c|c|c|c|c|c|}
\hline Procedure order & Order number & Number & Fixed transportation Cost & Variable cost & Date of delivery \\
\hline 1 & \multirow{6}{*}{$\begin{array}{l}1 \\
3 \\
5 \\
2 \\
4 \\
6\end{array}$} & 100 & 500 & \multirow{6}{*}{$\begin{array}{l}2.0 \\
3.0 \\
1.9 \\
2.8 \\
3.2 \\
2.3\end{array}$} & 60 \\
\hline 2 & & 140 & 600 & & 40 \\
\hline 3 & & 200 & 400 & & 80 \\
\hline 4 & & 200 & 500 & & 80 \\
\hline 5 & & 180 & 600 & & 110 \\
\hline 6 & & 100 & 400 & & 100 \\
\hline
\end{tabular}

\subsection{Scheduling Results and Analysis}

In the experiment, 20 ants were set up. The pheromone renewal mechanism was the optimal one. The Volatilization Coefficient of pheromone was $0.1, \alpha=1, \beta$ $=2$, and the initial concentration of pheromone was 2 . Q_density plus $=2000$, V_update base $=$ V_objection (initial iteration) - 1500. The penalty factor $\mathrm{Pi}$ for each order is set as follows: Order 1 is 100 , Order 2 is 80 , Order
3 is 200 , Order 4 is 150 , Order 5 is 150 , and Order 6 is 130 . For convenience, the unit inventory cost is set at 0.1 price units. The experimental results show that the optimal total objective function is 6513.8 price units. The combined transportation scheme is as follows: 5, 6 orders are combined transportation, and the rest orders are transported separately. Specific scheduling schemes are shown in Fig. 3 (O1-1 represents one process of an order).

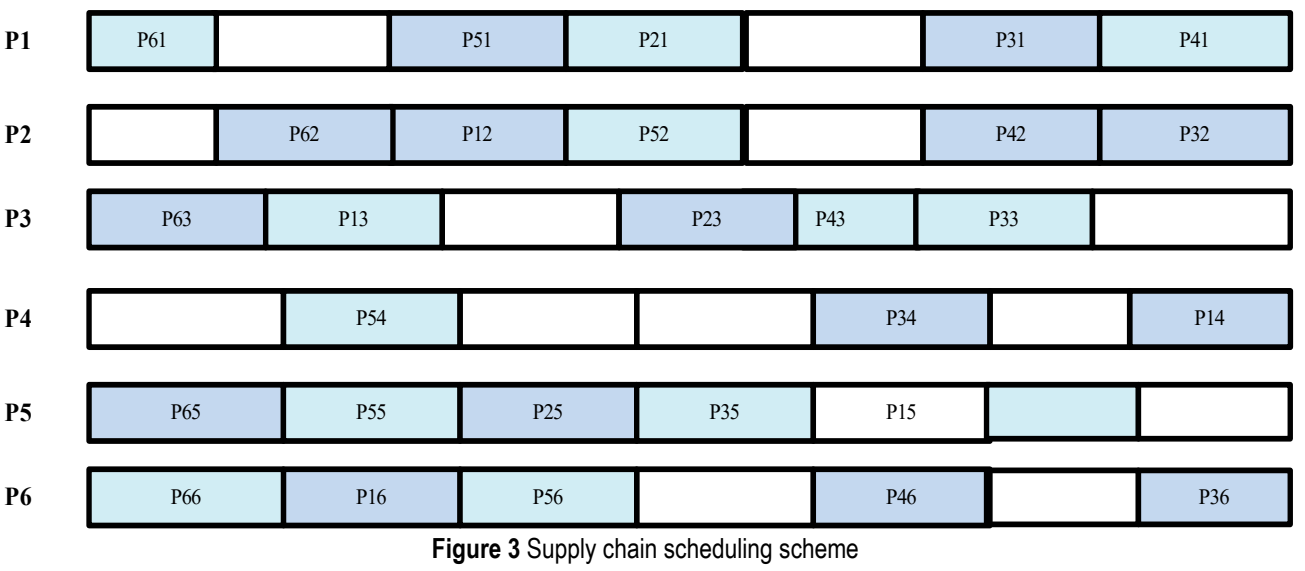

Table 4 Detailed cost sheet for each order

\begin{tabular}{|c|c|c|c|c|c|}
\hline$\overline{\tilde{d}}$ & $\begin{array}{l}\vec{w} \\
0 \\
0 \\
00 \\
.0 \\
0 \\
0 \\
0 \\
0 \\
0\end{array}$ & 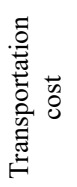 & 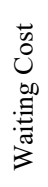 & 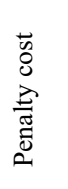 & 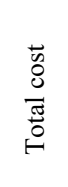 \\
\hline 1 & 189 & 700 & 1 & 0 & 1783 \\
\hline 2 & 294 & 1070 & 3.3 & 0 & 7124 \\
\hline 3 & 263 & 1030 & 0.3 & 0 & 1206 \\
\hline 4 & 264 & 1187 & 5.4 & 0 & 6514 \\
\hline 5 & 376 & 590 & 1.6 & 0 & 3387 \\
\hline 6 & 150 & 440 & 4.5 & 0 & 2859 \\
\hline
\end{tabular}

(1) Analysis of optimization results

Ideally, if there is no delivery deadline, each order will be produced at the minimum cost. Therefore, without considering the inventory cost, the objective function value of 5, 6 orders combined transportation is 6493.55 price units. In practice, as shown in Tab. 4 and Fig. 4 , the result is 6513.8 price units, with a difference of 20.25 price units and 15.5 price units of inventory cost. The actual difference among them is 4.75 price units, and the difference is very small. It can be concluded that the optimization results of the proposed algorithm are very close to the ideal state, which shows that the performance of the proposed algorithm is very good.

Tab. 5 summarizes the running time results of several typical algorithms under similar instance backgrounds and model assumptions. It can be seen that compared with the 269 minutes required by the best algorithm, multipopulation ant colony algorithm, this algorithm takes 13 
minutes and the solving speed is more than ten times faster (see Fig. 5). Therefore, compared with the previous algorithms, the proposed algorithm has achieved better results in solving performance and speed.

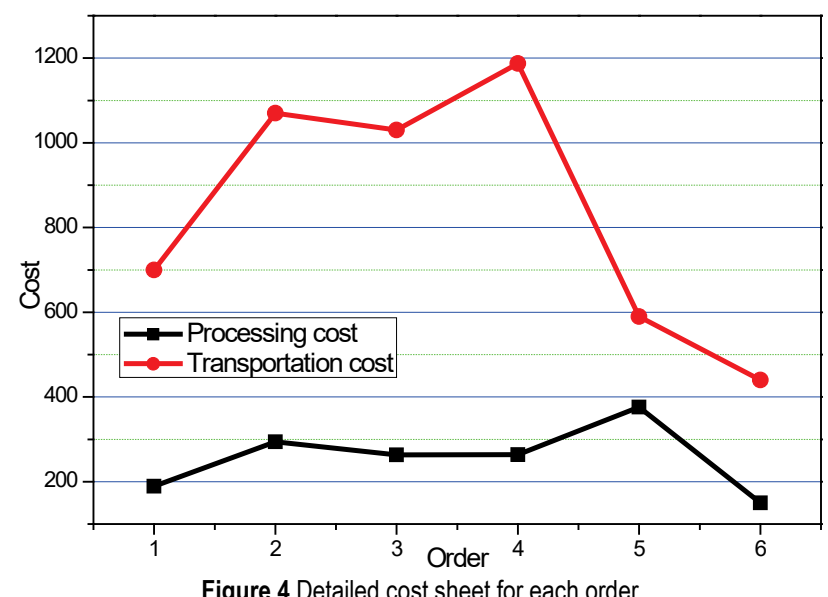

Table 5 Comparing the results of different algorithms

\begin{tabular}{|c|c|c|c|}
\hline $\begin{array}{c}\text { Different calculation } \\
\text { methods }\end{array}$ & Language & $\begin{array}{c}\text { Average } \\
\text { running time }\end{array}$ & $\begin{array}{c}\text { Number of } \\
\text { ants }\end{array}$ \\
\hline $\begin{array}{c}\text { Multi-population ant } \\
\text { colony algorithm }\end{array}$ & Java & 270 & 130 \\
\hline $\begin{array}{c}\text { Single population ant } \\
\text { colony algorithm }\end{array}$ & Java & 1535 & 130 \\
\hline Genetic algorithm & $\mathrm{C}$ & 513 & 50 \\
\hline $\begin{array}{c}\text { Adjacent exchange } \\
\text { algorithms }\end{array}$ & $\mathrm{VB}$ & 14 & 30 \\
\hline
\end{tabular}

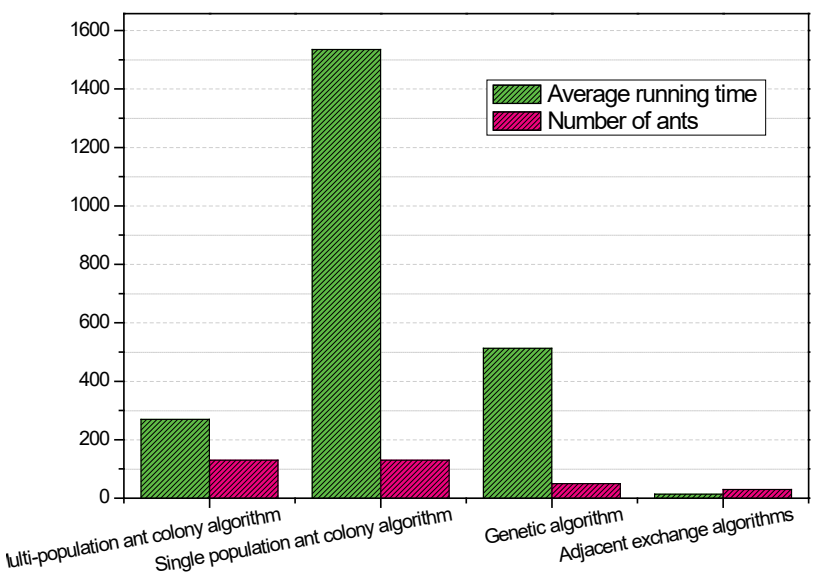

Figure 5 Comparing the results of different algorithms

\section{CONCLUSION}

Enterprises can jointly establish a supply chain, strengthen the level of information sharing among enterprises, firmly establish a three-in-one supply chain joint system of cost, security, and service, and reduce cost barriers between supply chains. It is also possible to diversify the likelihood risks through business cooperation among enterprises, thereby reducing the amount of unnecessary inventory security. Under the supply chain mechanism, safety inventory management not only relates to enterprise service and product costs, but also affects the delivery period of enterprise services and products, further affecting the service level of enterprises, and ultimately affects the market image and core competitiveness of enterprises. By establishing a simple mathematical model of joint inventory management, we can conclude that joint inventory management can save the inventory cost of the whole supply chain more than traditional inventory management. In joint inventory management, the upstream and downstream enterprises of supply chain establish a cooperative relationship through joint inventory. The supply and demand sides determine the optimal inventory level from the perspective of optimal supply chain, and then allocate the benefits of cooperation through game theory to optimize the inventory management of supply chain as a whole.

\section{REFERENCES}

[1] Gunjan, S., et al. (2019). Swarm intelligence approaches in supply chain management: potentials, challenges and future research directions. Supply Chain Management: An International Journal, 24(1), 107-123. https://doi.org/10.1108/SCM-02-2018-0070

[2] Taleizadeh, A. A., Niaki, S. T. A., \& Wee, H. M. (2013). Joint single vendor-single buyer supply chain problem with stochastic demand and fuzzy lead-time. Knowledge-Based Systems, 48(Complete), 1-9. https://doi.org/10.1016/j.knosys.2013.03.011

[3] Yong, W., et al. (2017). Cooperation and profit allocation in two-echelon logistics joint distribution network optimization. Applied Soft Computing, 56, 143-157. https://doi.org/10.1016/j.asoc.2017.02.025

[4] Jiang, N., Zhang, L. L., \& Yu, Y. (2015). Optimizing Cooperative Advertizing, Profit Sharing, and Inventory Policies in a VMI Supply Chain: A Nash Bargaining Model and Hybrid Algorithm. IEEE Transactions on Engineering Management, 62(4), 449-461. https://doi.org/10.1109/TEM.2015.2469684

[5] Liu, J. \& Xie, K. (2017). Emergency materials transportation model in disasters based on dynamic programming and ant colony optimization. Kybernetes, 46(4), 656-671. https://doi.org/10.1108/K-02-2016-0028

[6] Zhou, W. Q., Chen, L., \& Ge, H. M. (2013). A multi-product multi-echelon inventory control model with joint replenishment strategy. Applied Mathematical Modelling, 37(4), 2039-2050. https://doi.org/10.1016/j.apm.2012.04.054

[7] Zamarripa, M. A., Aguirre, A. M., Méndez, C. A., et al. (2013). Mathematical programming and game theory optimization-based tool for supply chain planning in cooperative/competitive environments. Chemical Engineering Research and Design, 91(8), 1588-1600. https://doi.org/10.1016/j.cherd.2013.06.008

[8] Chang, P. L., Chou, Y. C., \& Huang, M. G. (2005) A (r, r, Q) inventory model for sparse parts involving equipment criticality. International Journal of Production Economics, 97(1), 66-74. https://doi.org/10.1016/j.jpe.2004.06.048

[9] Hong, B. H., How, B. S. \& Lam, H. L. (2016). Overview of sustainable biomass supply chain: from concept to modelling. Clean Technologies and Environmental Policy, 18(7), 2173-2194. https://doi.org/10.1007/s10098-016-1155-6

[10] Sanjoy, P., Ruhul, S., \& Daryl, E. (2016). Managing risk and disruption in production-inventory and supply chain systems: A review. Journal of Industrial \& Management Optimization, 12(3), 1009-1029. https://doi.org/10.3934/jimo.2016.12.1009

[11] Rad, R. S. \& Nahavandi, N. (2018). A novel multi-objective optimization model for integrated problem of green closed loop supply chain network design and quantity discount. Journal of cleaner production, 196(20), 1549-1565. https://doi.org/10.1016/j.jclepro.2018.06.034

[12] Baykasoğlu, A., et al. (2019). Development of a Web-Based 
Decision Support System for Strategic and Tactical Sustainable Fleet Management Problems in Intermodal Transportation Networks. In: Lean and Green Supply Chain Management. Springer, Cham, 189-230. https://doi.org/10.1007/978-3-319-97511-5_7

[13] Uthayakumar, R. \& Priyan, S. (2013). Pharmaceutical supply chain and inventory management strategies: Optimization for a pharmaceutical company and a hospital. Operations Research for Health Care, 2(3), 52-64. https://doi.org/10.1016/j.orhc.2013.08.001

[14] Park, K. J. \& Kyung, G. (2014). Optimization of total inventory cost and order fill rate in a supply chain using PSO. The International Journal of Advanced Manufacturing Technology, 70(9-12), 1533-1541. https://doi.org/10.1007/s00170-013-5399-6

[15] Yao, X. \& Askin, R. (2019). Review of supply chain configuration and design decision-making for new product. International Journal of Production Research, 57(7), 22262246. https://doi.org/10.1080/00207543.2019.1567954

[16] Soni, H. N. \& Patel, K. A. (2015). Optimal policies for integrated inventory system under fuzzy random framework. The International Journal of Advanced Manufacturing Technology, 78(5-8), 947-959. https://doi.org/10.1007/s00170-014-6695-5

[17] Hamdi, F., et al. (2018). Optimization of a supply portfolio in the context of supply chain risk management: literature review. Journal of Intelligent Manufacturing, 29(4), 763788. https://doi.org/10.1007/s10845-015-1128-3

[18] Pakhira, N., Maiti, M. K., \& Maiti, M. (2017). Two-Level Supply Chain of a Seasonal Deteriorating Item with Time, Price, and Promotional Cost Dependent Demand under Finite Time Horizon. American Journal of Mathematical and Management Sciences, 36(3), 1-24. https://doi.org/10.1080/01966324.2017.1334605

[19] Mousavi, S. M., Alikar, N., \& Niaki, S. T. A. (2016). An improved fruit fly optimization algorithm to solve the homogeneous fuzzy series-parallel redundancy allocation problem under discount strategies. Soft Computing, 20(6), 2281-2307. https://doi.org/10.1007/s00500-015-1641-5

[20] Büyükkaramikli, N. C., Gürler, Ü., \& Alp, O. (2014). Coordinated Logistics: Joint Replenishment with Capacitated Transportation for a Supply Chain. Production and Operations Management, 23(1), 110-126. https://doi.org/10.1111/poms.12041

[21] Jiang, J., Wu, D., Chen, Y. et al. (2019). Fast artificial bee colony algorithm with complex network and naive bayes classifier for supply chain network management. Soft Computing, 23(24), 13321-13337. https://doi.org/10.1007/s00500-019-03874-y

[22] Ye, F. \& Wang, Z. (2013). Effects of information technology alignment and information sharing on supply chain operational performance. Computers \& Industrial Engineering, 65(3), 370-377. https://doi.org/10.1016/j.cie.2013.03.012

[23] Nourifar, R., Mahdavi, I., Mahdavi-Amiri, N. et al. (2018). Optimizing decentralized production-distribution planning problem in a multi-period supply chain network under uncertainty. Journal of Industrial Engineering International, 14(2), 367-382. https://doi.org/10.1007/s40092-017-0229-3

[24] Ali Roozbeh, N., Hemmati Far, M., \& Taghi Akhavan Niaki, S. (2014). A fuzzy vendor managed inventory of multi-item economic order quantity model under shortage: An ant colony optimization algorithm. International Journal of Production Economics, 155, 259-271. https://doi.org/10.1016/j.ijpe.2013.07.017

[25] Jiseong, N., \& Jong Soo, K. (2019). Cooperative green supply chain management with greenhouse gas emissions and fuzzy demand. Journal of Cleaner Production, 208, 1421-1435. https://doi.org/10.1016/j.jclepro.2018.10.124

[26] Rad, R., Nahavandi, N., Husseinzadeh Kashan, A., \&
Zegordi, S. H. (2018). An integrated closed-loop supply chain configuration model and supplier selection based on offered discount policies. International Journal of Engineering, 31(3), 440-449.

https://doi.org/10.5829/ije.2018.31.03c.06

[27] Javad, S., Mohsen Mousavi, S., \& Taghi Akhavan Niaki, S. (2016). Optimizing an inventory model with fuzzy demand, backordering, and discount using a hybrid imperialist competitive algorithm. Applied Mathematical Modelling, 40(15-16), 7318-7335. https://doi.org/10.1016/j.apm.2016.03.013

[28] Zaidan, A. A., et al. (2019). A new hybrid algorithm of simulated annealing and simplex downhill for solving multiple-objective aggregate production planning on fuzzy environment. Neural Computing and Applications, 31(6), 1823-1834. https://doi.org/10.1007/s00521-017-3159-5

[29] Du, Baigang \& Guo, Shunsheng. (2016). Production planning conflict resolution of complex product system in group manufacturing: a novel hybrid approach using ant colony optimization and Shapley value. Computers \& Industrial Engineering, 94, 158-169. https://doi.org/10.1016/j.cie.2015.12.015

[30] Jiang, Z., et al. (2018). Dynamical Analysis of a Phytoplankton-Zooplankton System with Harvesting Term and Holling III Functional Response. International Journal of Bifurcation and Chaos, 28(13), 1850162. https://doi.org/10.1142/S0218127418501626

[31] Singh, R., Vashishath, M., \& Kumar, S. (2019). Ant colony optimization technique for edge detection using fuzzy triangular membership function. International Journal of System Assurance Engineering and Management, 10(1), 1-6. https://doi.org/10.1007/s13198-019-00768-y

[32] Ghosh, M., Guha, R., Sarkar, R., et al. (2019). A wrapperfilter feature selection technique based on ant colony optimization. Neural Computing and Applications, 1-19. https://doi.org/10.1007/s00521-019-04171-3

[33] Wang, Z., Huang, X., \& Shi, G. (2011). Analysis of nonlinear dynamics and chaos in a fractional order financial system with time delay. Computers \& Mathematics with Applications, 62(3), 1531-1539. https://doi.org/10.1016/j.camwa.2011.04.057

[34] Xin, B., Peng, W., Kwon, Y. et al. (2019). Modeling, discretization, and hyperchaos detection of conformable derivative approach to a financial system with market confidence and ethics risk. Advances in Difference Equations, 2019, 138. https://doi.org/10.1186/s13662-019-2074-8

[35] Li, F., Zhang S., \& Meng, X. (2019). Dynamics analysis and numerical simulations of a delayed stochastic epidemic model subject to a general response function. Computational and Applied Mathematics, 38(95). https://doi.org/10.1007/s40314-019-0857-x

[36] Dong, H, Guo, B., \& Yin, B. (2016). Generalized fractional supertrace identity for Hamiltonian structure of NLS-MKdV hierarchy with self-consistent sources. Analysis and Mathematical Physics, 6(2), 199-209. https://doi.org/10.1007/s13324-015-0115-3

[37] Liu, T. \& Dong, H. (2019). The Prolongation Structure of the Modified Nonlinear Schrodinger Equation and Its InitialBoundary Value Problem on the Half Line via the RiemannHilbert Approach. Mathematics, 7(2), 170. https://doi.org/10.3390/math7020170

[38] Luo, Q., Wang, H., Zheng, Y., et al. (2019). Research on path planning of mobile robot based on improved ant colony algorithm. Neural Computing and Applications, 2019(1), 112. https://doi.org/10.1007/s00521-019-04172-2

[39] Zhang, Z., Wang, T., Chen, Y., et al. (2019). Design of type2 Fuzzy Logic Systems Based on Improved Ant Colony Optimization. International Journal of Control, Automation and Systems, 17(2), 536-544. https://doi.org/10.1007/s12555-017-0451-1 


\section{Contact information:}

\section{Wenfang YU}

College of Economics and Management,

Shandong University of Science and Technology,

Qingdao, Shandong 266590, China

\section{Guisheng HOU}

College of Economics and Management,

Shandong University of Science and Technology,

Qingdao, Shandong 266590, China

\section{Pengcheng XIA}

Corresponding author

College of Materials Science and Engineering,

Shandong University of Science and Technology,

Qingdao, Shandong 266590, China

E-mail: xpc328@126.com

\section{Jingjing LI}

College of Mathematics and Systems Science,

Shandong University of Science and Technology,

Qingdao, Shandong 266590, China 